\title{
Successful Induced Breeding of a Bagrid Catfish, Mystus Dibrugarensis in Captive Condition
}

\author{
Bhenila Bailung* and Biswas SP \\ Department of Life Sciences, Dibrugarh University, Assam, India
}

\begin{abstract}
Four induced breeding exercises on the Bagrid catfish species, Mystus dibrugarensis were conducted in Chinese circular eco hatchery system. Experiment was conducted in two conditions. One in breeding pool (marked as A) with continuous showering of water and another was one in round tank having duck mouth at floor (marked as B) and maintaining a mild water circulation. Synthetic hormone, ovaprim was used to induce the species at different doses $(0.4-0.6 \mathrm{mg} / \mathrm{kg})$ in each breeding trial. Spawning was observed after a latency period of $5-8 \mathrm{~h}$ under an optimum temperature ranged of $27-29^{\circ} \mathrm{C}$. Dissolved oxygen level was found different in both experimental conditions. The egg output was recorded in tank 'A' was 2786-4765 no. and tank 'B' was 1217-1893 no. Fertilization rate was recorded between $34.83-77.54 \%$ in tank ' $A$ ' and $55.87-58.32 \%$. Hatching rate was also recorded as $20.61-74.32 \%$ in tank ' $A$ ' and $41.49-46.06 \%$ in tank ' $B$ '.
\end{abstract}

Keywords: Eco hatchery; Ovaprim; Spawning; Dissolved oxygen

\section{Introduction}

In India, basically carps are breed for bulk of production of seed. But catfishes have been always favoured for experimental studies. Ramaswami et al. [1] first used pituitary gland extract for inducing Heteropneustes fossilis and Clarias batrachus to breed. Catfishes are the most accepted fish variety in the Indian market for their delicacy. Induced breeding practice of catfishes in commercial sector is also becoming popular in recent years due to their high market price and hardy nature. Introduction of induced breeding of fishes in captivity enhance the quality of seed, minimizes the chances of cross breeding that generally happens in nature and predation pressure. The potential of induced breeding in captive condition is to enhance the population and conservation of endemic species.

Mystus dibrugarensis, first described from Dibrugarh (27029/N and 94054/) in upper Assam by Chaudhuri (1913), is a small sized silurid (family Bagridae) and fairly common in the rivers and beels of upper Brahmaputra basin. Locally known as singora, this carnivorous bottom dwelling is regarded as ornamental fish although these are exclusively used as food fish in Assam [2]. The ornamental fish trade earns foreign exchange, besides serving as a source of employment to rural population. Moreover, this fish species have high demand and price in the north-east India. To fulfill its high demand breeding and captive management in large scale is necessary. High fecundity of this species makes it a potential species in commercial aquaculture.

However, scientific information on the spawning season and induced breeding of Mystus species are limited in literature. The few published works available are Ray [3-7]. Up to now there is no information on the reproductive biology and captive breeding of Mystus dibrugarensis. In view of the lack of knowledge on the breeding practice of Mystus dibrugarensis this present experiment was carried out.

\section{Methods and Methodology}

\section{Collection of brooders}

Live and healthy specimens of $\mathrm{M}$. dibrugarensis were collected from different fish landing sites of Dihing River of Dibrugarh district specially from its confluence with Brahmaputra River i.e. Dihingmukh
(27026/N and 94042/) between January and April when maturing specimens are available. The collections were made in 2013 and 2014.

\section{Acclimatization of species}

Collected specimens were first acclimatized sex-wise in separate earthen ponds $(3 \times 3 \times 1 \mathrm{~m})$ having sandy bottom from January to March. Aquatic macrophytes like Pistia and Lemna were provided in pond water to make the habitat natural. In late March, brooders were transferred to separate cemented tank $(2.4 \times 2.4 \times 0.7 \mathrm{~m})$ and were kept there until breeding experiment was conducted. The tanks were provided with the facility of water circulation, aeration and replenishment. The tanks were provided with a mixture of sand and small gravel with smooth surface at the bottom. Aquatic plants like water hyacinth (Eichhornia crassipes) and Pistia was placed in both the tanks and covered with net to prevent fish from jumping out. Fishes were provided with mosquito larvae, small insect, plankton and also occasionally with dried tubifex, prawns, and fishes. In late April, breeding trial was conducted. Before injection both male and female fishes gone through showering process in a same tank separated by net.

\section{Experimental lay-out}

The present experiment was carried out in two set maintaining water depth of $45 \mathrm{~cm}$. One set was carried out in breeding tank providing continuous showering of water marked as 'A' and another one carried out in cementing round tank having duck mouth at the floor and marked as ' $\mathrm{B}$ '. Mild water circulation was maintained throughout during experiment. Limnological parameters like dissolved oxygen (DO), free $\mathrm{CO}_{2}$ and alkalinity were recorded by adopting APHA [6] protocol. $\mathrm{PH}$ and water temperature were recorded with the

*Corresponding author: Bhenila Bailung, Department of Life Sciences, Dibrugarh University, Assam, India, Tel: 9401173922; E-mail: bhenila.bailung@gmail.com

Received September 23, 2014; Accepted October 29, 2014; Published November 02, 2014

Citation: Bailung B, Biswas SP (2014) Successful Induced Breeding of a Bagrid Catfish, Mystus Dibrugarensis in Captive Condition. J Aquac Res Development 5 : 281. doi:10.4172/2155-9546.1000281

Copyright: (C) 2014 Bailung B, et al. This is an open-access article distributed under the terms of the Creative Commons Attribution License, which permits unrestricted use, distribution, and reproduction in any medium, provided the original author and source are credited. 
help of a portable digital $\mathrm{pH}$ meter and thermometer graduated up to $110^{\circ} \mathrm{C}$ respectively. Water hyacinth was placed in breeding tanks in two patterns- some were tied up with rope to keep them stagnant and some were placed freely.

\section{Induced breeding of $M$. dibrugarensis}

Mature male was identified by a slightly pointed genital papilla while mature females by a swollen abdomen and by slightly pressing along the ventral side of the fish for oozing of eggs. Synthetic hormone, ovaprim was applied in the brooders of both the sets and released in the tanks. Before injecting hormone, length and weight of the brooders were taken. The length ranged from $8.5-12.3 \mathrm{~cm}$ for male and $12-14.4$ $\mathrm{cm}$ for female. The mean weight was $6.7 \mathrm{~g}$ and $8.3 \mathrm{~g}$ for male and female respectively. Different hormone doses like $0.4,0.6,0.8,1.0 \mathrm{mg} / \mathrm{kg}$ was injected below the pectoral fin during evening time. After injection fishes were released to marked tanks 'A' and 'B' in 2:1 (male: female) and 3:1 ratio respectively. To compare the efficacy of male different sex ratio was maintained in both tanks. To transfer the eggs after fertilization a hapa was prepared by markin cloth in a cementing tank and water depth was maintained to $45 \mathrm{~cm}$. Percentage of fertilization and hatching rates were recorded to determine the effectiveness of hormone, using the following formula:

$$
\% \text { Fertilization }=\frac{\text { No.of fertilized egg }}{\text { Total no.of eggs }} \times 100 \text { (Alam et al., 2006) }
$$

Hatching rate was calculated by following Islam et al., 2011. 500 fertilized eggs were isolated in happa and then hatching rate was calculated.

$$
\% \text { Hatching }=\frac{\text { No.of hatching appeared }}{\text { No.of eggs in subsample }} \times 100
$$

\section{Results}

Breeding trails were done four times by applying different doses of hormone $(0.4-1.0 \mathrm{ml} / \mathrm{kg})$ in each breeding trials. Same dose of ovaprim hormone was injected to both male and female. Injected fishes were released in tanks and observed that after 6-7 h they approached each other. Mating takes place near the bunch of water hyacinth where they release egg and milt. Eggs being of sticky type were deposited on the roots of aquatic plant. Spawning occurred after 2-3 h of latency period and continued for 1-2 $\mathrm{h}$. On the next morning aquatic plants bearing sticky eggs were removed and transferred in to happa of markin cloth placed in tank and the water depth was maintained to $45 \mathrm{~cm}$ for further analysis. It was observed that fishes preferred to deposit their eggs in stagnant hyacinth than free floating ones. It was observed that in tank 'A' each of the hormone dose shows positive result of fertilization and hatching. But tank 'B' did not show any fertilization after inducing hormone dose 0.4 and $1.0 \mathrm{mg} / \mathrm{kg}$.

Limnological parameters of both 'A' and 'B' tank during different breeding trials and hatching tank were recorded in Table 1 . Standardization of results of each breeding trails along with fertilization rate and hatching rate in two marked ' $\mathrm{A}$ ' and ' $\mathrm{B}$ ' were calculated Tables 2 and 3 .

\section{Discussion}

In the present experiment spawning was occurred within 5-8 h of hormone injection. Both male and female were injected with same dose of hormone in two sets of condition. In tank 'A' where sex ratio was maintained in 2:1 male and female respectively showed better

\begin{tabular}{|c|c|c|c|c|c|}
\hline Tank & ${ }_{\mathbf{P}} \mathbf{H}$ & DO (mg/l) & $\begin{array}{c}\text { Free } \mathbf{C O}_{\mathbf{2}} \\
\mathbf{( m g / l )}\end{array}$ & $\begin{array}{c}\text { Alkalinity } \\
(\mathbf{m g} / \mathbf{l})\end{array}$ & $\begin{array}{c}\text { Water temp } \\
\left({ }^{\circ} \mathbf{C}\right)\end{array}$ \\
\hline A & $7.1-7.3$ & $10.2-11.6$ & $2.2-3.52$ & $52-57$ & $27-29$ \\
\hline B & $7.1-7.3$ & $7.6-8.7$ & $4.4-4.9$ & $48-53$ & $27-29$ \\
\hline Happa (Av.) & 7.4 & 7.7 & 4.5 & 48 & 25 \\
\hline
\end{tabular}

Table 1: Limnological parameters of breeding tanks and hatching happa.

Trial Male (10 no) Female (5 no) Dose Latency Fertilization Hatchling (\%)

\begin{tabular}{|c|c|c|c|c|c|c|c|c|} 
Trial & \multicolumn{2}{|c|}{ Male (10 no) } & \multicolumn{2}{c|}{ Female (5 no) } & Dose & Latency & Fertilization & Hatchling (\%) \\
\hline & $\mathrm{L} \mathrm{(cm)}$ & $\mathrm{W}(\mathrm{g})$ & $\mathrm{L}(\mathrm{cm})$ & $\mathrm{W}(\mathrm{g})$ & $\mathrm{ml} / \mathrm{kg}$ & $\operatorname{period}(\mathrm{h})$ & $(\%)$ & $(\%)$ \\
\hline 1 & $9.2-12.3$ & 91 & $13-14.2$ & 62 & 0.6 & $6-7$ & 77.06 & 69.29 \\
\hline 2 & $8.5-11.4$ & 88 & $13.3-14.4$ & 69 & 0.8 & $5-7$ & 77.54 & 74.32 \\
\hline 3 & $8.7-12$ & 89 & $12-13$ & 60 & 1.0 & $6-7$ & 75.30 & 46.30 \\
\hline 4 & $9-12$ & 83 & $12-13.2$ & 59 & 0.4 & $6-7$ & 34.83 & 20.61 \\
\hline
\end{tabular}

Table 2: Breeding trials of $M$. dibrugarensis in tank ' $A$ '.

\begin{tabular}{|c|c|c|c|c|c|c|c|c|}
\hline Trial & \multicolumn{2}{|c|}{ Male (15 no) } & \multicolumn{2}{|c|}{ Female (5 no) } & Doses & Latency & Fertilization & Hatchlings \\
\hline & $\mathrm{L}(\mathrm{cm})$ & $\mathrm{W}(\mathrm{g})$ & $\mathrm{L}(\mathrm{cm})$ & $\mathrm{W}(\mathrm{g})$ & $(\mathrm{ml} / \mathrm{kg})$ & period $(\mathrm{h})$ & $(\%)$ & $(\%)$ \\
\hline 1 & $9.2-12$ & 65 & $13-14.3$ & 68 & 0.6 & $7-8$ & 55.87 & 41.49 \\
\hline 2 & $8.8-11$ & 69 & $13.3-14.4$ & 72 & 0.8 & $6-8$ & 58.32 & 46.06 \\
\hline 3 & $8.8-10.7$ & 63 & $12-14$ & 66 & 1.0 & & - & - \\
\hline 4 & $8.5-11$ & 59 & $12-14.3$ & 69 & 0.4 & & - & - \\
\hline
\end{tabular}

Table 3: Breeding trails of $M$. dibrugarensis in tank ' $\mathrm{B}$ '.

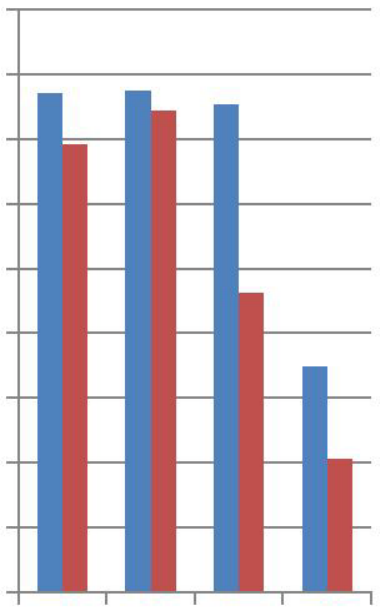

Figure 1: $\%$ of fertilization and hatching rate tank ' $A$ '.

fertilization rate than tank ' $\mathrm{B}$ ' where sex ratio was 3:1 (male and female). Out of different doses of hormone applied to fishes $0.8 \mathrm{mg} / \mathrm{kg}$ gave better spawning rate. Moreover appropriate timing is one factor which also affects the spawning and fertilization of egg. It was seen that at last trial fertilization rate was low because milt of most of the male species were decreased. This experiment was conducted in two conditions. Tank 'A' providing continuous showering of water showed better spawning and fertilization rate than slow water circulated tank ' $\mathrm{B}$ ' (Figures 1 and 2). From this experiment it may be concluded that the selected species Mystus dibrugarensis needs water circulation in the period of their spawning and for fertilization of eggs. But hatching was occurred in confined water. Islam et al. [4] observed $57-80 \%$ fertilization rate and 32-56\% hatching rate in case of Mystus vittatus with different doses of hormone ranging from $4-6 \mathrm{mg} / \mathrm{kg}$ in male and $8-12 \mathrm{mg} / \mathrm{kg}$ in female. Ray, 2005 found $90 \%$ fertilization rate that yielded hatchings about $80 \%$ of fertilized eggs in Mystus gulio. 
Citation: Bailung B, Biswas SP (2014) Successful Induced Breeding of a Bagrid Catfish, Mystus Dibrugarensis in Captive Condition. J Aquac Res Development 5: 281. doi:10.4172/2155-9546.1000281

Page 3 of 3

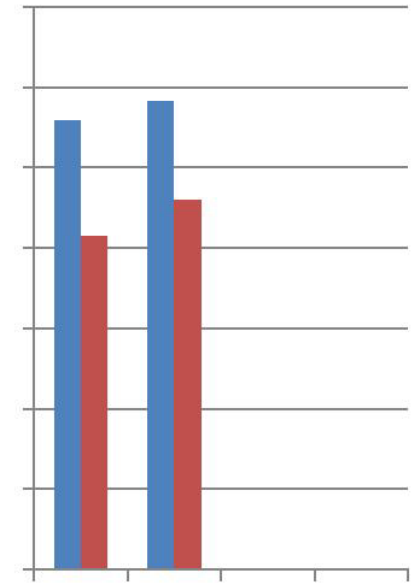

Figure 2: $\%$ of fertilization and hatching rate tank 'B'

Induced breeding of Mystus dibrugarensis was successfully carried out by using synthetic hormone ovaprim. A successful captive breeding programme is likely to include aspects such as identification, collection, stocking, breeding, rearing and maintenance. Breeding of M. dibrugarensis is regulated by several environmental factors, such as dissolve oxygen, free carbon-di-oxide, total alkalinity, temperature, rainfall and food. Various environmental factors like rainfall and some water parameters affects on the distribution and survivability of species. Proper control of water parameters, health of brooders and appropriate dose of hormone is the basis of successful induced breeding. Proper rearing and culture will further increase the population.

\section{Acknowledgment}

The authors are thankful to the authority of Dibrugarh University and NFDB Hyderabad for providing financial facility. Thanks are also due to Mr. T. Alam, owner of Alam and sons farm for providing necessary facilities during the period of study.

\section{References}

1. Ramaswami LS, Sudararaj B (1956) Inducing spawning in the Indian catfish Science 123: 1080.

2. Das JN, Biswas SP (2008) A handbook of ornamental fishes of the Brahmaputra basin, Eastern Book House, Guwahati, India.

3. Ray PK (2005) Induced breeding and larval rearing of brackish water catfish, Mystus gulio in salinity- free water. Fishing chime 25.

4. Islam S, Shah S, Rahi L (2011) Study of fecundity and induced breeding of Mystus vittatus. Bangla J Zoolo 39: 205-212.

5. Gupta S, Banerjee S (2013) Studies on reproductive biology of Mystus tengara (Ham.-Buch., 1822), a freshwater catfish of West Bengal, India. Intern J Aquat Biol 1: 175-184.

6. APHA (1998) Standard methods for estimation of water and waste and water, 20th edition, American Public Health Association, Washington DC, USA.

7. Alam MJ, Begum M, Islam MA, Pal HA (2006) Spawning behavior and induced breeding of an esturine cat fish, Mystus gulio (Ham.). Bangladesh Journal of Fishery Resources 10: 101-109. 